\title{
Impact of beliefs about pain control on perceptions of illness in surgical patients
}

\author{
Jarosław Jerzy Sak', Dariusz Sagan², Jakub Pawlikowski', Michał Wiechetek ${ }^{3}$, Marek Jarosz ${ }^{3}$ \\ ${ }^{1}$ Department of Ethics and Human Philosophy, Medical University of Lublin, Poland \\ ${ }^{2}$ Chair and Department of Thoracic Surgery, Medical University of Lublin, Poland \\ ${ }^{3}$ Department of Social Psychology and Psychology of Religion, The John Paul II Catholic University of Lublin, Poland
}

Sak JJ, Sagan DM, Pawlikowski J, Wiechetek M, Jarosz M. Impact of beliefs about pain control on perceptions of illness in surgical patients. Ann Agric Environ Med. 2016; 23(1): 144-147. doi: 10.5604/12321966.1196870

\begin{abstract}
Objectives. Adequacy of pain management in surgical patients is a major contributor to overall treatment outcomes and positive illness perceptions. However, it may be subjectively predetermined by a patient's beliefs about pain control. This study assesses the relationships between beliefs about pain control and perceptions of illness in thoracic surgical patients. Materials and method. A total of 135 patients (72 women and 63 men; mean age $58.4 \pm 14.25 y$ ) were enrolled in the questionnaire study based on the Beliefs about Pain Control Questionnaire (BPCQ) by S. Skevington and the Multidimensional Essence of Disease and IIIness Scale (MEDIS) by J. Sak. Analyses were conducted with use of the k-means clustering technique and one-way ANOVA.

Results. Applied classification revealed 3 different clusters of patients with regard to their beliefs about pain control: 1) weak, undifferentiated pain control; 2) intensified influence of chance pain control; 3) strong undifferentiated pain control. Significant differences in illness perceptions between clusters were disclosed in 3 MEDIS dimensions: self-realization constraints ( $F=4.70 ; p=0.01 ; 1$ vs. 3 ), mental dysfunction ( $F=3.44, p=0.04 ; 1$ vs. 3 ) and physical dysfunction $(F=3.10, p=0.05$; 1 vs 2). Patients in cluster 3 demonstrated a greater feeling of self-realization constraints and mental dysfunction than in cluster 1, whereas patients in cluster 2 perceived physical dysfunction as a greater distress than those in cluster 1.

Conclusions. Beliefs about pain control significantly influence illness perceptions, and thus may affect the results of treatment in surgical patients. Psychological modelling of beliefs about pain control may offer a valuable way to improve overall clinical outcomes.
\end{abstract}

\section{Key words}

Beliefs, illness perception, psychology, pain control, self-realization, surgery

\section{INTRODUCTION}

The psychology of medicine emphasizes the need for dealing with the negative emotional effects of medicine becoming mechanistic and of its dehumanization. Research on patients' apprehensions of an illness they suffer from, may indicate novel ways to counteract these unfavourable phenomena. Physicians often fail to recognize that such apprehensions are common among patients. While dealing with patients' disorders and their emotions, physicians refer to the set of meanings acquired during professional training. Understanding patients' social and psychological needs, as well as recognizing their problems with a proper body and psyche constitute, an important task for medical personnel [1, 2]. The key psychological issue for those afflicted with surgical diseases is to discover the sense of everyday pursuits and activities. It is especially important for the future ability of patients to restart social life, and to perform specific functions in society, e.g. their family or work place. Toombs [3] claims that an illness is genuinely and fundamentally experienced by a patient as

[...] a global sense of disorder - a disorder which includes the disruption of the lived body (with the concurrent disturbance of self and world) and the changed relation

Address for correspondence: Jakub Pawlikowski, Department of Ethics and Human Philosophy, Szkolna 18, 20-124 Lublin, Poland

E-mail: jpawlikowski@wp.pl

Received: 11 December 2012; accepted: 5 February 2014 between body and self (manifested through objectification and alienation from one's body) [3].

Explaining this definition of an illness, Toombs states that the detailed consideration of 'a global sense of disorder' reveals that it is a life experience composed of such things as the loss of: integrity, certainty, control, freedom of acting and family life. The original experience of losing integrity may appear in various forms. In the most basic sense it appears as awareness of bodily weakness or injury. A disease disturbs the fundamental integrity of the body and self, resulting, e.g. in the situation that the body which used to be naturally involved in a process of living and not to attract the attention of the mind, is now becoming an undesired object of one's awareness. A badly functioning object-body reveals itself as a strange and originally secret being which, in fact, appears to be beyond the control of the sick individual. The experience of body otherness is experienced acutely during patients' talks with their physicians $[3,4]$.

Phenomenological analyses indicate that an illness constitutes an altered state of 'being-in-the-world' that may be of limited duration or may endure until the end of an individual's life [5]. Usually, the sick individual, experiencing an altered existence, is not able to continue regular life activity, work or entertainment [4]. Toombs points out the subsequent exclusion of a patient from the society in which he or she has worked, studied or pursued his/her life goals so far [3]. The exclusion phenomenon also refers to the patient's relation to 
his/her family, for the family members can continue their participation in the main stream of life activity [6]. Thus, the existential aloneness becomes a necessary element of an illness itself [7]. Many authors emphasize the extremely important fact that an altered existence means not only disturbing everyday activity or lowering the level of engagement in achieving life goals, but also changing essentially the normal way of perceiving reality - changing the experience of time and space $[3,8,9]$. A disease limits individuals' everyday experiences through the pain, suffering, disability, or even the loss of the meaning of life [3]. A patient is a person who simultaneously experiences an illness and, on the basis of his/her own social and psychological experience, provides the meanings to it [5]. In clinical practice, the medical staff are often unaware that what they think about a patient's disease differs greatly from the perceptions and feelings of the patient $[10,11]$.

The phenomenon of illness is associated with constraining, even to some low degree, the personal freedom of a human being [12]. Physical disability is not the only element of this constraint. Other essential elements of personal freedom are spiritual freedom and beliefs about health and pain control. Chronic non-cancer pain research is evident and abundant in the literature of clinical medicine and the psychology of medicine $[1,7,9,11,13,14,15,16,17,18]$. It can be hypothesized that redefining beliefs about pain control by a person with a surgical disease is an essential psychological mechanism of overcoming the otherness of his/her body and the disorder itself. It seems to be an important research endeavour to capture a relation between beliefs about pain control and the perception of illness as a phenomenon affecting various dimensions of human existence.

The aim of this study was to identify and define relationships between beliefs about pain control and the perception of various aspects of disease in patients with thoracic surgical diseases.

\section{MATERIALS AND METHOD}

A total of 135 patients undergoing surgical treatment in the thoracic surgery department were enrolled in the study (72 women and 63 men; mean age $58.4 \pm 14.25 y$ ). The study group included 32 patients with mediastinal non-malignant diseases, 27 with pulmonary non-malignant nodules, 36 with emphysema, 7 with hyperhydrosis, 25 with thoracic trauma and 12 with pleural non-malignant diseases. Sociodemographic and clinical characteristics of patients are presented in Table 1. This non-homogeneous structure of the study group reflects the cross-section of non-malignant diseases hospitalized in actual thoracic surgery wards. The survey was carried out anonymously between January October 2010, after informed consent to take part in the study had been obtained from each individual patient. The approval of Bioethical Committee at the Medical University in Lublin, Poland, was obtained before starting the research.

The study was performed using the Beliefs about Pain Control Questionnaire (BPCQ) by Skevington [19] in the Polish adaptation by Juczyński [20], k-means clustering technique, and the Multidimensional Essence of Disease and Illness Scale (MEDIS) by Sak [21].

The BPCQ developed by Skevington consists of 13 items assigned to 3 subscales measuring beliefs about internal (personal control) of pain (IS), beliefs that powerful others (i.e. doctors) can control pain (PD), and beliefs that pain is controlled by chance events $(\mathrm{CH})$. Higher scores in these subscales indicated stronger endorsements of the respective beliefs $[8,16,19]$. Previous psychometric testing had shown reasonable internal consistency (Cronbach's alpha) in the chronic pain and non-patient groups for each subscale of BPCQ: internal control pain - IS ( $\alpha=0.73)$, powerful others control pain - PD $(\alpha=0.82)$, chance happening control pain - $\mathrm{CH}(\alpha=0.56)[19]$.

The typology of the study group with regard to the BPCQ scale was performed using the k-means clustering technique, which allows dividing a set of studied items into groups (types) without any previously existing external criteria.

The MEDIS developed by Sak [21], refers to the research strategies used in the psychology of health that aim to answer the question about common understanding of illness [6]. The MEDIS scale is designed for examining colloquial expressions in order to test general beliefs about the essence of an illness. The scale helps to evaluate what 'being ill' means to a given respondent, without referring to any specific disease. The scale consists of 28 items assigned to 5 factors describing:

- Self-realisation constraints (10 items);

- Mental dysfunction (5 items);

- Physical dysfunction (5 items);

- Infection (4 items);

- Social withdrawal (4 items).

Previous psychometric testing had shown reasonable internal consistency (Cronbach's alpha) for each of the factors on the MEDIS scale:

- Self-realization constraints $(\alpha=0.87)$;

- Mental dysfunction $(\alpha=0.77)$;

- Physical dysfunction $(\alpha=0,63)$;

- Infection ( $\alpha=0.64)$;

- Social withdrawal $(\alpha=0,59)$.

Table 1. Sociodemographic and clinical characteristics of the study group $[N=135 ;$ males $=63(47 \%) ;$ females $=72(53 \%)]$

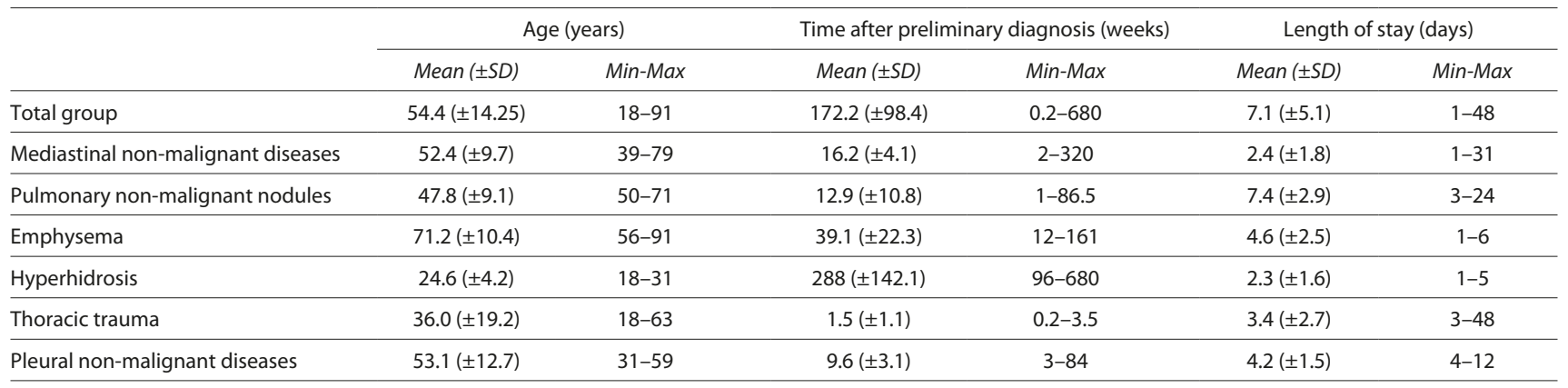


Because of the different numbers of items in these dimensions, the arithmetic averages of scores obtained from respondents were calculated separately for each of 5 factors. A 5-point Likert-like scale (where 1 equals 'strongly disagree' and 5 equals 'strongly agree') assigned to each of 28 items helps evaluate to what degree a respondent agrees with a given description of 'being ill'. The higher average of scores (min. - 1.0; $\max$ - 5.0 ) in a given dimension is, the more importance is assigned to the dimension in understanding the essence of 'being ill' [21].

Statistical analyses were performed using SPSS version 14.0 software. Differences in illness perception between clusters of pain control were assessed using one-way ANOVA analysis of variance.

\section{RESULTS}

Applied classification using $\mathrm{k}$-means clustering revealed 3 different clusters of patients with regard to their beliefs about pain control: type 1 - weak undifferentiated pain control; type 2 - intensified influence of chance pain control; type 3 - strong undifferentiated pain control type (Tab. 2; Fig. 1). Analysis of the BPCQ data collected for k-means clustering disclosed that the internal control of pain belief (IS) was overexpressed among patients in 2 clusters of beliefs about pain control: weak undifferentiated type (1) and strong undifferentiated type (3). Whereas an overwhelming domination of chance happening pain control $(\mathrm{CH})$ was found in the type with intensified influence of chance pain control type (2).

Subsequently, illness perception was assessed using the MEDIS scale in the 3 clusters of beliefs about pain control. Significant differences in illness perceptions between the clusters were disclosed in 3 MEDIS dimensions:

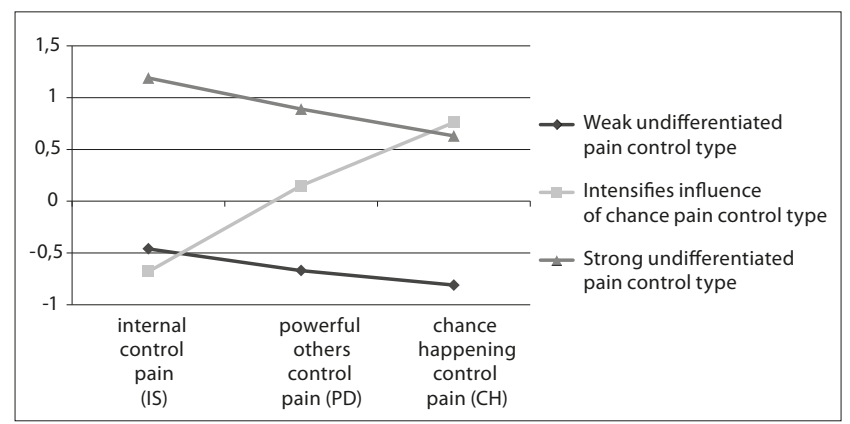

Figure 1. Pain control types revealed in k-means clustering analysis of BPCQ factors

- self-realization constraints $(\mathrm{F}=4.70 ; \mathrm{p}=0.01$;

- post hoc NIR 1 vs. 3), mental dysfunction $(\mathrm{F}=3.44, \mathrm{p}=0.04$;

- post hoc NIR 1 vs. 3$)$ and physical dysfunction $(\mathrm{F}=3.10$, $\mathrm{p}=0.05$

- post hoc NIR 1 vs. 2) (Tab. 3).

ANOVA and post-hoc tests showed that patients in cluster 3 demonstrated a greater feeling of self-realization constraints and mental dysfunction than in cluster 1 , whereas patients in cluster 2 perceived physical dysfunction as a greater distress than those in cluster 1. Differences with regard to perception of the disease as an infection and to social withdrawal were insignificant. In all clusters, perception of the disease as a physical dysfunction dominated over other illness perception dimensions (Fig. 2).

\section{DISCUSSION}

Results of the MEDIS analysis performed revealed that in all identified pain control clusters the feeling of physical dysfunction dominated over other dimensions of illness

Table 2. Characteristics of pain control types revealed in k-means clustering analysis of BPCQ factors (IS, PD, CH)

\begin{tabular}{|c|c|c|c|c|c|c|}
\hline Cluster & $\mathrm{N}$ & BPCQ factors & Mean & SD & Min & Max \\
\hline & & internal control of pain (IS) & -0.46 & 0.602 & -2.15 & 0.67 \\
\hline \multirow[t]{3}{*}{ Weak undifferentiated pain control type } & 62 & powerful others control pain (PD) & -0.67 & 0.828 & -2.77 & 0.92 \\
\hline & & chance happenings control pain $(\mathrm{CH})$ & -0.81 & 0.677 & -2.44 & 0.26 \\
\hline & & internal control of pain (IS) & -0.68 & 0.577 & -1.79 & 0.14 \\
\hline \multirow[t]{2}{*}{ Intensified influence of chance pain control type } & 31 & powerful others control pain (PD) & 0.15 & 0.858 & -2.15 & 1.32 \\
\hline & & internal control of pain (IS) & 1.19 & 0.603 & 0.14 & 2.08 \\
\hline \multirow[t]{2}{*}{ Strong undifferentiated pain control type } & 42 & powerful others control pain (PD) & 0.89 & 0.446 & -0.11 & 1.32 \\
\hline & & chance happenings control pain $(\mathrm{CH})$ & 0.63 & 0.697 & -1.48 & 1.42 \\
\hline
\end{tabular}

Table 3. Illness perceptions (the MEDIS factors) in the BPCQ clusters (results of ANOVA)

\begin{tabular}{|c|c|c|c|c|c|c|c|c|c|}
\hline \multirow[t]{2}{*}{ The MEDIS factors } & \multicolumn{2}{|c|}{$\begin{array}{l}\text { Weak undifferentiated pain } \\
\text { control type } \\
\text { (1) }\end{array}$} & \multicolumn{2}{|c|}{$\begin{array}{l}\text { Intensified influence of chance } \\
\text { pain control type } \\
(2)\end{array}$} & \multicolumn{2}{|c|}{$\begin{array}{l}\text { Strong undifferentiated pain } \\
\text { control type } \\
\text { (3) }\end{array}$} & \multirow[t]{2}{*}{$\mathrm{F}$} & \multirow[t]{2}{*}{$\mathrm{p}$} & \multirow[t]{2}{*}{$\begin{array}{c}\text { Post hoc } \\
\text { NIR }\end{array}$} \\
\hline & M & SD & M & SD & M & SD & & & \\
\hline Self-realization constraints & 2.98 & 0.93 & 3.36 & 0.96 & 3.57 & 1.08 & 4.70 & 0.01 & $1: 3$ \\
\hline Mental dysfunction & 3.20 & 0.91 & 3.39 & 0.96 & 3.76 & 1.33 & 3.44 & 0.04 & $1: 3$ \\
\hline Physical dysfunction & 4.02 & 0.69 & 4.35 & 0.58 & 4.28 & 0.72 & 3.10 & 0.05 & $1: 2$ \\
\hline Infection & 3.76 & 0.83 & 3.93 & 0.78 & 4.07 & 0.95 & 1.66 & 0.19 & - \\
\hline Social withdrawal & 2.79 & 0.87 & 2.98 & 0.88 & 2.80 & 0.97 & 0.48 & 0.62 & - \\
\hline
\end{tabular}




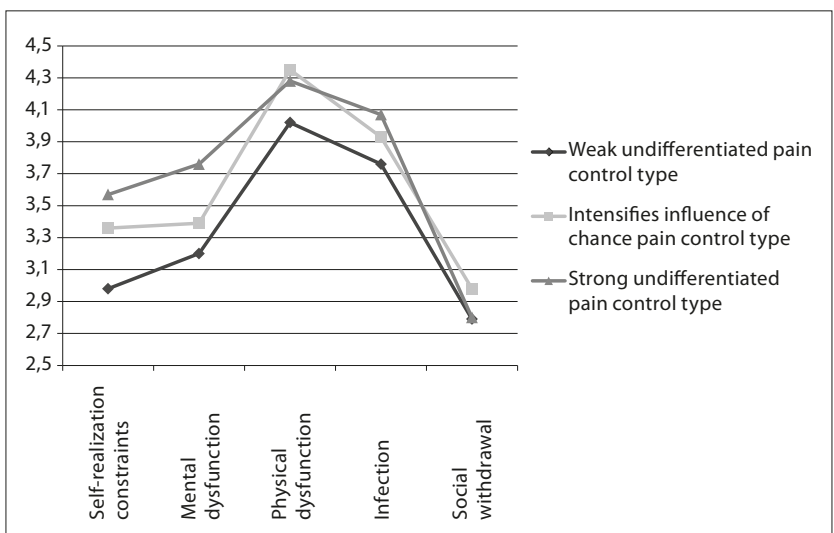

Figure 2. Differences in illness perception (according to the MEDIS) between BPCQ clusters.

perception. However, the patients representing the strong undifferentiated pain control type demonstrated a greater feeling of self-realization constraints and mental dysfunction than patients with weak undifferentiated pain control type. These findings demonstrate that beliefs about pain control significantly influence illness perceptions. It has been reported previously that illness perception may exert a remarkable impact on the overall results of treatment in surgical patients [10]. Thus, extending further the presented analysis, it may be concluded that beliefs about pain control may influence the overall results of treatment in surgical patients. The demonstrated relationships can serve as a practical guide for medical personnel regarding the information that needs to be provided to patients about their disease, indicating which areas of information require most attention, and contributing to improved treatment outcomes.

It is very interesting that patients representing intensified influence of chance events pain control type, perceive illness's physical dysfunction as a higher complaint than patients with weak undifferentiated pain control type. This suggests that chance happening pain control is associated with perceiving illness through the prism of physical dysfunction.

\section{CONCLUSIONS}

The results of the current study may be practically useful for medical personnel who deal with sick people on an everyday basis. It is common that patients are lonely in their attempt to create the perception of their condition $[5,6]$; in pursuit of feeling less insecure, they search for information that would help them understand what has happened to them and what the possible consequences of a given disease are $[6$, $8,9]$. All too often, the collected information is incomplete, unverified, or - what is equally disadvantageous - unclear. Such a situation fails to help regain the lost integrity of one's body and self [3]. Medical personnel should be aware of the fact that their duty is not only to treat a patient, but also to provide honest information about a disease and causes of pain and to provide some psychological support [10]. With regard to this support, it seems reasonable to take into account some forms of assistance alleviating the process of patients getting accustomed with their diseases $[13,15]$. It is well known that no one would understand an individual better than another person with an analogical disorder. Previous reports and the presented results suggest that the information provided by medical personnel to patients with surgical diseases may have direct influence on the individual's perception of pain control.

The presented results show that beliefs about pain control significantly influence illness perceptions, and may therefore affect the results of treatment in surgical patients. The psychological modeling of beliefs about pain control may offer a valuable way to improve overall clinical outcomes.

\section{REFERENCES}

1. Fields HL. Core curriculum for professional education in pain: a report of the Task Force on Professional Education of the International Association for the Study of Pain. Seattle: IASP Press; 1995.

2. Kapusta A. Life Circle, Time and the Self in Antoni Kępiński's Concept of Information Metabolism. Filosofija. Sociologija [Philosophy. Sociology], 2007; 1: 44-49.

3. Toombs KS. The Meaning of Illness. A Phenomenological Account of the Different Perspectives of Physician and Patient. Dordrecht: Kluwer Academic Publishers; 2003.

4. Kapusta A. Can Mental Illness be Naturalised? In Miłkowski M. \& Talmont-Kamiński K. (Eds.), Beyond Description. Normativity in Naturalised Philosophy; London: College Publications; 2010: 261-275.

5. Cassell EJ. The subjective in clinical judgment. In Engelhardt HT.Jr, (Ed.) Clinical Judgment: A Critical Appraisal. Dordrecht: D. Reidel; 1979.

6. Turk DC, Rudy TE, Salovey P. Implicit models of illness. J Behav Med. 1986; 9: 453-474.

7. Bargiel-Matusiewicz K, Krzyszkowska A. Dispositional optimism and coping with pain. Eur J Med Res. 2009; 14, Suppl 4: 271-4.

8. Brown CA. Occupational Therapists' Beliefs Regarding Treatment Options for People with Chronic Pain. Br J Occup Ther. 2002; 65: 3.

9. Donovan MI, Evers K, Jacobs P. When there is no benchmark: designing a primary care-based chronic pain management programme from the scientific basis up. J Pain Symp Manag. 1999; 18: 38-48.

10. Sagan D Sak J, Wiechetek M, Pawlikowski J, Olszewska E, Cieślak T. Differences in psychological perception of lung cancer between patients, medical staff and medical students. Eur J Cardiothorac Surg. 2012 Mar; 41(3): 607-11.

11. LeFort SM, Gray-Donald K, Rowat KM, Jeans ME. Randomised controlled trial of a community-based psychoeducation programme for the self-management of chronic pain. Pain 1998; 74: 297-306.

12. Sak J, Sagan D, Wiechetek M, Pawlikowski J. Suboptimal perception of illness due to self-realization constraints impairs psychological welfare in surgical patients. Eur J Cardiothorac Surg. 2012Apr; 41(4): 824-8.

13. Brown CA. The beliefs of people with chronic pain in relation to 'important' treatment components. Eur J Pain. 2004; 8: 325-33.

14. Ekstein MP, Weinbroum AA. Immediate postoperative pain in orthopedic patients is more intense and requires more analgesia than in post-laparotomy patients. Pain Med. 2011; 12(2): 308-13. doi: 10.1111/j.1526-4637.2010.01026.x.

15. Turk DC. Biopsychosocial perspectives on chronic pain. In: Gatchel RJ, Turn DC, (Eds.), Psychological approaches to pain management: a practitioner's handbook. New York: Guilford Press; 1996.

16. Jones D, Ravey J, Steedman W. Developing a measure of beliefs and attitudes about chronic non-malignant pain: a pilot study of occupational therapists. Occup Ther Int. 2000; 7: 232-45.

17. Koukis I, Argiriou M, Dimakopoulou A, Panagiotakopoulos V, Theakos $\mathrm{N}$, Charitos C. Use of continuous subcutaneous anesthetic infusion in cardiac surgical patients after median sternotomy. J Cardiothorac Surg. 2008; 25(3): 2 .

18. Von Korff M, Moore J, Lorig K, Cherkin DC, Saunders K, Gonzalez VM, Laurent D, Rutter C, Comite F. A randomised trial of a layperson led self-management group intervention for back pain patients in primary care. Spine 1998; 23: 2608-15.

19. Skevington SM. A standardised scale to measure beliefs about pain control (BPCQ): a preliminary study. Psychol Health. 1990; 4: 221-32.

20. Juczyński Z. Narzędzia pomiaru w promocji i psychologii zdrowia. Warszawa: Pracownia Testów Psychologicznych Polskiego Towarzystwa Psychologicznego; 2001.

21. Sak J. Wielowymiarowa Skala Istoty Choroby jako nowe narzędzie badawcze w naukach o zdrowiu [The Multidimensional Essence of Disease and Illness Scale as a New Tool in Health Sciences]. Zagadnienia Naukoznawstwa/Probl Sci Sci. 2010; 184: 303-311. 